\title{
Dose-dependent genotype effects of BDNF Val66Met polymorphism on default mode network in early stage Alzheimer's disease
}

\author{
Pin-Hsuan Lin ${ }^{1}$, Shih-Jen Tsai ${ }^{2,3}$, Chi-Wei Huang ${ }^{1,5}$, Liu Mu-En ${ }^{3}$, Shih-Wei Hsu ${ }^{4}$, \\ Chen-Chang Lee ${ }^{4}$, Nai-Ching Chen ${ }^{1,5}$, Ya-Ting Chang ${ }^{1,5}$, Min-Yu Lan ${ }^{5}$ and Chiung- \\ Chih Chang ${ }^{5}$ \\ ${ }^{1}$ Department of Health and Beauty, Shu-Zen College of Medicine and Management, Kaohsiung, Taiwan \\ 2 Psychiatric Department of Taipei Veterans General Hospital, Taipei, Taiwan \\ ${ }^{3}$ Psychiatric Division, School of Medicine, National Yang-Ming University, Taipei, Taiwan \\ ${ }^{4}$ Department of Radiology, Kaohsiung Chang Gung Memorial Hospital, Chang Gung University College of Medicine, Kaohsiung, \\ Taiwan \\ ${ }^{5}$ Department of Neurology, Cognition and Aging Center, Kaohsiung Chang Gung Memorial Hospital, Chang Gung University \\ College of Medicine, Kaohsiung, Taiwan \\ Correspondence to: Chiung-Chih Chang, email: neur099@adm.cgmh.org.tw \\ Keywords: Alzheimer's disease, genetic dosage effect, anatomical structural covariance, default mode network, brain-derived \\ neurotrophic factor, Gerotarget \\ Received: June 10,2016 Accepted: July 22, $2016 \quad$ Published: August 02, 2016
}

\section{ABSTRACT}

In humans, brain-derived neurotrophic factor (BDNF) has been shown to play a pivotal role in neurocognition, and its gene contains a functional polymorphism (Val66Met) that may explain individual differences in brain volume and memoryrelated activity.

In this study, we enrolled 186 Alzheimer's disease (AD) patients who underwent 3D T1 magnetic resonance imaging, and explored the gray matter (GM) structural covariance networks (SCN). The patients were divided into three groups according to their genotype: Met/Met $(n=45)$, Val/Met $(n=86)$ and Val/Val $(n=55)$. Seedbased analysis was performed focusing on four SCN networks. Neurobehavioral scores served as the major outcome factor.

Only peak cluster volumes of default mode medial temporal lobe network showed significant genotype interactions, of which the interconnected peak clusters showed dose-dependent genotype effects. There were also significant correlations between the cognitive test scores and interconnected-cluster volumes, especially in the orbitofrontal cortex.

These findings support the hypothesis that BDNF rs6265 polymorphisms modulate entorhinal cortex-interconnected clusters and the valine allele was associated with stronger structural covariance patterns that determined the cognitive outcomes.

\section{INTRODUCTION}

Neurotrophins are a group of molecules which play a key role in regulating neural survival, development and maintenance. The most abundant neurotrophic factor is brain-derived neurotrophic factor (BDNF) [1, $2]$ and has been reported to be of clinical significance in mediating the hippocampus network function $[3,4]$. Activity-dependent BDNF secretion has been reported to be required for long-term potentiation and depression [5, 6] while impaired patterns of discrimination and learning deficits have been observed in BDNF knockout mice [7]. The salient pathological feature in Alzheimer's disease (AD) is hippocampal network degeneration, and BDNF has been shown to play a protective role in attenuating amyloid-related toxicity $[5,8]$.

In humans, the BDNF gene has been mapped to chromosome 11p14.1. A common single nucleotide 
polymorphisms (SNP) consisting of a missense change of the coding exon at position 66 (Val66Met, rs6265) has been shown to produce non-conservative amino acid changes (Val to Met). The Met allele carriers have been shown to have poorer episodic memory, and this may be reflected in lower activities of BDNF with impaired neuronal processing and trafficking [9]. A recent metaanalysis study [10] showed no significant associations between the BDNF Val66Met polymorphism and the risk of developing AD in dominant (Met $v s$. Val/Val), recessive (Met/Met vs. Val) and additive (Met/Met vs. Val/Val) carriers. Another meta-analysis reported that the Met66 allele conferred susceptibility to AD in women but not in men [11].

The influence of BDNF polymorphisms on human cognition has been linked with its impact on changes in brain structure. However, whether the Met allele leads to worse outcomes is controversial. Smaller brain volumes have been reported in Met carriers in the hippocampal and dorsolateral prefrontal areas [12], hippocampus [13], hippocampal, amygdala, thalamus, fusiform gyrus and frontal gyrus [14]. Other studies have reported no significant differences in hippocampal volume, whole brain volume or memory scores between Met carriers and Val homozygotes [15], and no significant genetic effects of BDNF on cognitive performance [16]. A protective role of the Met allele in regional gray matter (GM) volume and neurocognitive performance have been reported [1719]. Given the role of BDNF as a crucial mediator in the maintenance of neuronal function, it is not known whether the Val66Met genotype is related to large-scale network modulation in patients with AD.

Recent research has suggested that highly related regions show covariance in morphometric characteristics, so called structural covariance. Structural covariance networks (SCNs) can be used to test the influence of the genotype with careful control of other factors. Three SCNs have been reported to be relevant to patients with $\mathrm{AD}$ : default mode network (DMN) [20-22], salience network [23] and executive control network [24, 25]. A recent report suggested that the DMN may be comprised of multiple, spatially dissociated but interactive components [26], of which two subsystems are particularly relevant: the "medial temporal lobe subsystem", and the "dorsal medial prefrontal cortex subsystem" (or the midline core subsystem).

The potential mechanisms of genetic-based neurobiology are still under investigation, however a number of studies have highlighted how genetic variations [27-30], epigenetic [31, 32] or metabolic interactions [33] may affect organization of the brain or therapeutic programs [34]. In this study, we hypothesized that BDNF Val66Met functional polymorphisms may modulate the large-scale structural covariance pattern in patients with $\mathrm{AD}$, and that network alterations may also determine the neurobehavioral characteristics.

\section{RESULTS}

\section{Demographic data, cognitive data and NPI}

The demographic characteristics and neuropsychiatric test results of the three genotype groups are listed in Table 1. The Val66Met genotype distribution was in Hardy-Weinberg equilibrium. There were no significant differences in apolipoprotein E4 allele distribution, MMSE scores, total or individual CASI scores, NPI total scores or levels of cerebrovascular risk biomarkers among the groups.

\section{Patterns of structural associations in the patients and genetic variants}

Among the three BDNF genotypes and four seed regions (Figure 1A), there were no significant differences in the GM volumes of each seed (Figure 1B). Networks showing structural associations with the seed regions for each genotype are shown in Figure $1 \mathrm{C}$ and Supplementary Table 1-12.

In the entorhinal seed-based DMN networks, the Met/Met homozygotes showed no clusters with a voxel size $>100$ (Supplementary Table 1), while the Val/Met (voxel size $=53,366$; Supplementary Table 2 ) and Val/Val homozygotes (voxel size $=49,132$; Supplementary Table 3 ) showed clusters located in the para-hippocampus and sub-regions in the lateral temporal or frontal regions. In the DMN PCC seeds, the Met/Met homozygotes showed the greater numbers of voxels (voxel size $=167,815$; Supplementary Table 4) compared with the Val/Met group (voxel size $=81,020$; Supplementary Table 5) and Val/Val homozygotes (voxel size $=26,488$; Supplementary Table 6).

For the frontoinsular seed, the Met/Met homozygotes (voxel size $=47,064$; Supplementary Table 7 ) and Val/Met group (voxel size = 81,020; Supplementary Table 8) showed more extended voxels than the Val/Val homozygotes (voxel size $=1,142$; Supplementary Table 9). For the dorsolateral prefrontal seed, the Met/Met homozygotes showed significantly greater structural covariance in the executive network (voxel size $=58,075$; Supplementary Table 10) than the Val/Met group (voxel size $=35,720$; Supplementary Table 11) and Val/Val homozygotes (voxel size $=19,225$; Supplementary Table 12).

\section{Seed region volumes and relationships with the cognitive scores}

We first explored whether each seed region volume was correlated with the selected cognitive 
Table 1: Demographical characteristics and neuropsychiatric tests in the BDNF A homozygotes, G homozygotes and GA in Alzheimer's disease

\begin{tabular}{|c|c|c|c|c|}
\hline Group & $\begin{array}{l}\text { A homozygotes } \\
(n=45)\end{array}$ & $\begin{array}{l}\text { GA } \\
(n=86) \\
\end{array}$ & $\begin{array}{l}\text { G homozygotes } \\
(n=55)\end{array}$ & $P$ value \\
\hline Age & $73.6(6.6)$ & $73.4(8.8)$ & $73.5(8.6)$ & 0.99 \\
\hline Education (year) & $6.6(4.9)$ & $7.3(5.1)$ & $6.4(5.1)$ & 0.56 \\
\hline Apolipoprotein E4 carrier (positive case, \%) & $19,42.2 \%$ & $33,38.4 \%$ & $25,45.5 \%$ & 0.65 \\
\hline Sex (male/female) & $18 / 27$ & $46 / 40$ & $18 / 37$ & 0.44 \\
\hline Mini-Mental State Examination & $19.5(6.0)$ & $20.2(7.0)$ & $17.9(6.5)$ & 0.12 \\
\hline CASI total scores & $64.7(21.6)$ & $67.5(25.0)$ & $60.7(21.5)$ & 0.24 \\
\hline Short Term Memory & $4.5(3.9)$ & $5.6(3.9)$ & $4.1(3.6)$ & 0.05 \\
\hline Orientation & $11.9(5.3)$ & $12.6(5.7)$ & $10.6(5.3)$ & 0.11 \\
\hline Long Term Memory & $8.1(2.9)$ & $8.2(2.8)$ & $8.11(2.7)$ & 0.98 \\
\hline Language & $7.7(2.4)$ & $7.9(2.6)$ & $7.72(2.3)$ & 0.94 \\
\hline Drawing & $7.67(3.1)$ & $7.71(3.4)$ & $7.20(3.1)$ & 0.64 \\
\hline Executive function test scores & $25.0(8.9)$ & $25.2(9.4)$ & $23.2(8.4)$ & 0.40 \\
\hline Neuropsychiatric inventory total scores & $9.0(13.0)$ & $7.2(11.4)$ & $9.6(10.7)$ & 0.45 \\
\hline \multicolumn{5}{|l|}{ Cerebrovascular Risk Biomarkers } \\
\hline Homocysteine (umol/L) & $13.35(6.29)$ & $14.69(13.04)$ & $12.63(4.05)$ & 0.46 \\
\hline Hemoglobin-A1C (\%) & $6.21(1.67)$ & $6.23(1.34)$ & $9.61(1.21)$ & 0.99 \\
\hline Creatinine $(\mathrm{mg} \%)$ & $1.05(0.34)$ & $1.08(0.50)$ & $0.96(0.37)$ & 0.31 \\
\hline high-density lipoprotein (mg/dl) & $61.38(17.34)$ & $54.56(15.12)$ & $55.46(13.37)$ & 0.06 \\
\hline low-density lipoprotein (mg/dl) & $105.35(40.14)$ & $105.50(34.58)$ & $113.35(41.49)$ & 0.46 \\
\hline Total Cholesterol (mg/dl) & $194.13(42.39)$ & $182.05(37.25)$ & $197.46(39.61)$ & 0.06 \\
\hline Triglyceride (mg/dl) & $115.90(68.46)$ & $114.13(52.08)$ & $125.40(69.09)$ & 0.57 \\
\hline Hemoglobin $(\mathrm{g} / \mathrm{dl})$ & $13.39(1.66)$ & $13.43(1.80)$ & $13.27(1.34)$ & 0.86 \\
\hline Vitamin B12 (pg/dl) & $686.03(363.42)$ & $685.17(414.37)$ & $689.45(383.59)$ & 1.00 \\
\hline Folate (ng/dl) & $15.90(17.53)$ & $13.34(5.33)$ & $14.03(5.76)$ & 0.42 \\
\hline
\end{tabular}

Data are presented as mean (standard deviation) or number (percentage; \%)

Abbreviations: CASI, Cognitive Ability Screening Instrument; Attention, verbal fluency, abstract thinking, and mental manipulation sub-domain scores of the CASI were used to assess executive function. BDNF, brain APOE4 carriers were defined as the presence of one or two APOE4 alleles.

test (Supplementary Figure 1). The DMN entorhinal (Supplementary Figure 1A) and PCC (Supplementary Figure 1B) seed volumes both showed significant correlations with the MMSE scores, CASI total scores, short-term memory, orientation and EFT scores, while the PCC seed also showed significant correlations with CASI language and drawing scores. For the salience network, only the CASI short-term memory score showed a significant correlation with the frontoinsular seed volume (Supplementary Figure 1C). For the executive control network, the seed region volume showed significant correlations with all test scores (Supplementary Figure 1D). The correlations between the seed volume and test scores suggested greater clinical significance of the PCC seed and dorsolateral prefrontal seed on the prediction of overall cognitive test scores.

\section{Peak clusters showing significant interactions between genotypes (Val/Val > Met/Met or Val/Met $>$ Met/Met)}

For each seed, we further explored the genotypic interactions with regards to the topography showing differences in structural covariance between seed and peak clusters (Figure 2 and Supplementary Figure 2).

Only peak clusters connected to the right entorhinal seed (Table 2) showed topographic similarities in structural covariance in genotype group analysis (Figure 2A: Val/Val > Met/Met green clusters; Figure 2B: Val/ Met $>$ Met/Met red clusters). The spatially coherent overlapping regions were located in the sub-regions of the prefrontal lobes and PCC (Figure 2C), of which the 
Table 2: Connectivity differences between brain-derived neurotrophic factor genotypes with right entorhinal cortex as seed.

\begin{tabular}{|c|c|c|c|c|c|c|c|c|}
\hline \multirow[t]{2}{*}{ Main Cluster } & \multirow[t]{2}{*}{ Peak regions } & \multirow[b]{2}{*}{ Side } & \multicolumn{3}{|c|}{$\begin{array}{l}\text { Stereotaxic } \\
\text { coordinates }\end{array}$} & \multirow[t]{2}{*}{ Extent } & \multirow[t]{2}{*}{$\operatorname{Max} \mathbf{T}$} & \multirow[t]{2}{*}{$P$-value } \\
\hline & & & $x$ & $\mathrm{y}$ & $\mathrm{z}$ & & & \\
\hline \multicolumn{9}{|l|}{ Val/Met $>$ Met/Met } \\
\hline $\begin{array}{l}\text { Frontal inferio triangular } \\
\text { region }\end{array}$ & & $\mathrm{R}$ & 38 & 35 & 24 & 357 & 3.69 & $<0.001$ \\
\hline Inferior Temporal & & $\mathrm{L}$ & -48 & -25 & -24 & 341 & 3.67 & $<0.001$ \\
\hline \multirow[t]{3}{*}{ Superior Temporal Pole } & & $\mathrm{L}$ & -27 & 8 & -20 & 4931 & 3.61 & $<0.001$ \\
\hline & Anteiror Cingulum & L & -6 & 38 & -5 & s.c. & 3.5 & $<0.001$ \\
\hline & Rectus & $\mathrm{R}$ & 11 & 24 & -17 & s.c. & 3.29 & 0.001 \\
\hline \multirow[t]{3}{*}{ Precuneus } & & $\mathrm{R}$ & 8 & -45 & 15 & 820 & 3.3 & 0.001 \\
\hline & Posterior cingulum & $\mathrm{L}$ & -8 & -46 & 16 & s.c. & 3.29 & 0.001 \\
\hline & Precuneus & $\mathrm{L}$ & -12 & -52 & 21 & s.c. & 3.2 & 0.001 \\
\hline Inferior Temporal & & $\mathrm{L}$ & -53 & -46 & -14 & 379 & 3.28 & 0.001 \\
\hline Middle Frontal & & L & -35 & 38 & 18 & 143 & 3.27 & 0.001 \\
\hline \multirow[t]{3}{*}{ Inferior Temporal } & & $\mathrm{R}$ & 51 & -24 & -24 & 478 & 2.71 & 0.004 \\
\hline & Inferior Temporal & $\mathrm{R}$ & 48 & -33 & -24 & s.c. & 2.53 & 0.006 \\
\hline & Inferior Temporal & $\mathrm{R}$ & 56 & -42 & -15 & s.c. & 2.51 & 0.007 \\
\hline \multicolumn{9}{|l|}{$\mathrm{Val} / \mathrm{Val}>\mathrm{Met} / \mathrm{Met}$} \\
\hline \multirow[t]{3}{*}{ Middle Frontal } & & L & -35 & 38 & 16 & 1315 & 4.5 & $<0.001$ \\
\hline & Middle Frontal & $\mathrm{L}$ & -26 & 32 & 30 & s.c. & 3.3 & 0.001 \\
\hline & Middle orbital Frontal & $\mathrm{L}$ & -35 & 44 & -9 & s.c. & 3.13 & 0.001 \\
\hline \multirow[t]{3}{*}{$\begin{array}{l}\text { Frontal inferio triangular } \\
\text { region }\end{array}$} & & $\mathrm{R}$ & 38 & 32 & 24 & 938 & 4.24 & $<0.001$ \\
\hline & Middle Frontal & $\mathrm{R}$ & 41 & 24 & 33 & s.c. & 2.92 & 0.002 \\
\hline & Middle Frontal & $\mathrm{R}$ & 35 & 42 & 13 & s.c. & 2.65 & 0.005 \\
\hline \multirow[t]{3}{*}{ Superior Temporal Pole } & & $\mathrm{L}$ & -27 & 8 & -20 & 6427 & 4.02 & $<0.001$ \\
\hline & Rectus & $\mathrm{R}$ & 12 & 24 & -15 & s.c. & 3.65 & $<0.001$ \\
\hline & Anteiror Cingulum & $\mathrm{R}$ & 3 & 29 & -3 & s.c. & 3.59 & $<0.001$ \\
\hline \multirow[t]{3}{*}{$\begin{array}{ll}\text { Supplementary } & \text { Motor } \\
\text { Area } & \\
\end{array}$} & & L & -11 & -12 & 54 & 812 & 3.74 & $<0.001$ \\
\hline & Superior Frontal & L & -15 & 17 & 51 & s.c. & 3.17 & 0.001 \\
\hline & Superior Frontal & L & -17 & 8 & 48 & s.c. & 3.13 & 0.001 \\
\hline \multirow[t]{3}{*}{ Precuneus } & & L & -12 & -52 & 21 & 612 & 3.59 & $<0.001$ \\
\hline & Posterior cingulum & $\mathrm{R}$ & 3 & -42 & 9 & s.c. & 3.02 & 0.002 \\
\hline & Precuneus & $\mathrm{R}$ & 11 & -46 & 16 & s.c. & 2.91 & 0.002 \\
\hline Insula & & $\mathrm{R}$ & 47 & 3 & 0 & 1495 & 3.53 & $<0.001$ \\
\hline
\end{tabular}




\begin{tabular}{|c|c|c|c|c|c|c|c|c|}
\hline & Insula & $\mathrm{R}$ & 41 & -12 & -3 & s.c. & 2.86 & 0.003 \\
\hline & Insula & $\mathrm{R}$ & 39 & -15 & 9 & s.c. & 2.64 & 0.005 \\
\hline \multirow[t]{3}{*}{ Inferior Temporal } & & $\mathrm{L}$ & -47 & -25 & -24 & 1146 & 3.34 & 0.001 \\
\hline & Inferior Temporal & $\mathrm{L}$ & -53 & -46 & -15 & s.c. & 3.03 & 0.002 \\
\hline & Middle Temporal & $\mathrm{L}$ & -56 & -43 & -8 & s.c. & 2.81 & 0.003 \\
\hline SupraMarginal & & $\mathrm{L}$ & -54 & -46 & 28 & 123 & 3.01 & 0.002 \\
\hline \multirow[t]{5}{*}{ Middle Temporal } & & $\mathrm{R}$ & 48 & -5 & -27 & 171 & 2.98 & 0.002 \\
\hline & Inferior Temporal & $\mathrm{R}$ & 50 & -11 & -33 & s.c. & 2.48 & 0.008 \\
\hline & $\begin{array}{ll}\begin{array}{l}\text { Superior } \\
\text { Frontal }\end{array} & \\
\end{array}$ & $\mathrm{L}$ & -17 & 54 & 1 & 289 & 2.87 & 0.003 \\
\hline & Superior orbital frontal & $\mathrm{L}$ & -14 & 54 & -11 & s.c. & 2.59 & 0.005 \\
\hline & Middle orbital Frontal & $\mathrm{L}$ & -24 & 53 & -11 & s.c. & 2.57 & 0.006 \\
\hline \multirow[t]{3}{*}{ Middle Temporal } & & $\mathrm{L}$ & -44 & -63 & 21 & 115 & 2.73 & 0.004 \\
\hline & Insula & $\mathrm{L}$ & -35 & 18 & 0 & 188 & 2.55 & 0.006 \\
\hline & \begin{tabular}{|ll}
$\begin{array}{l}\text { Frontal } \\
\text { operculum }\end{array}$ & inferior \\
\end{tabular} & $\mathrm{L}$ & -39 & 14 & 13 & s.c. & 2.37 & 0.01 \\
\hline
\end{tabular}

Peak regions are within the Main cluster; $\mathrm{R}=$ right, $\mathrm{L}=\mathrm{left}$; $\mathrm{s} . \mathrm{c}=$ same cluster

Max T is the maximum T statistic for each local maximum. $P<0.01$ based on non-stationary cluster-extent False discovery rate correction.

peak clusters sharing greater topographic distributions in $\mathrm{Val} / \mathrm{Val}>\mathrm{Met} /$ Met than Val/Met $>$ Met/Met included the inferior orbital frontal, pregenual anterior cingulate cortex, para-hippocampus, PCC and dorsolateral prefrontal cortex (Figure 2D).
For the PCC (Supplementary Figure 2A), frontoinsular (Supplementary Figure 2B) and dorsolateral prefrontal (Supplementary Figure 2C) seeds, differences in covariance between $\mathrm{Val} / \mathrm{Val}>\mathrm{Met} / \mathrm{Met}$ or Val/Met $>$ Met/Met were located in different sub-regions of the brain

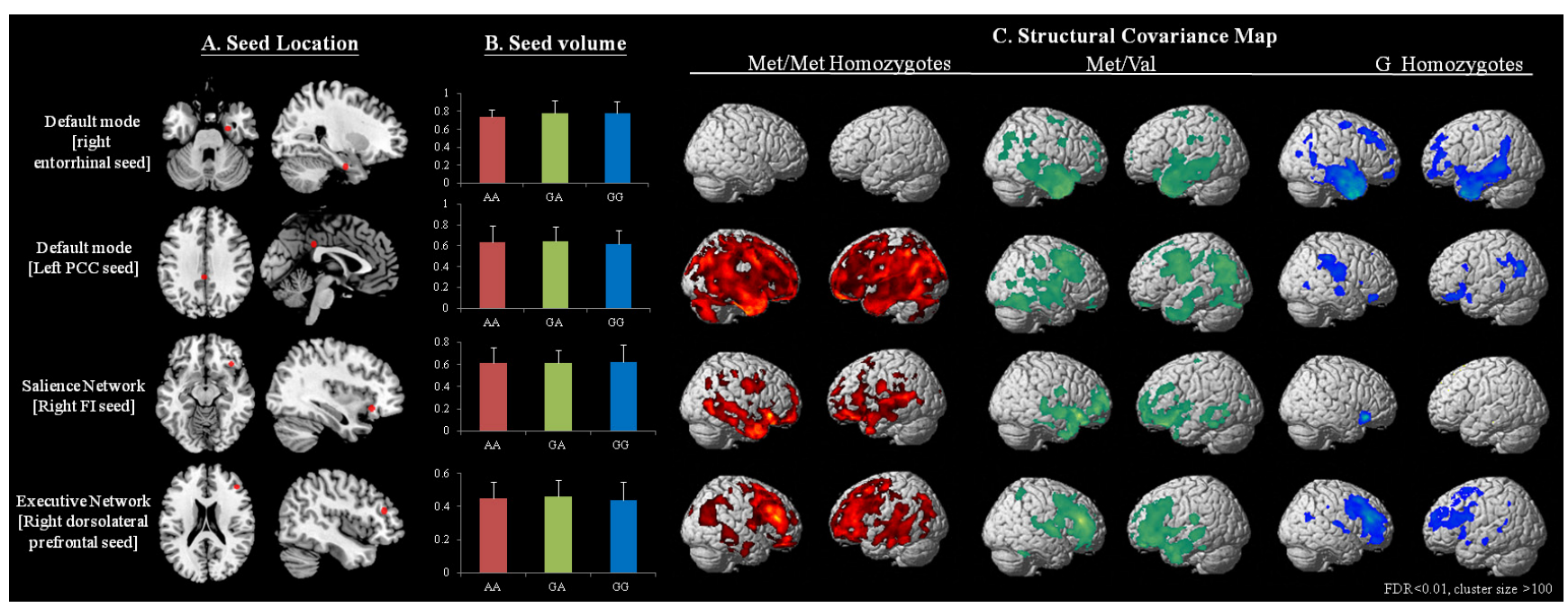

Figure 1: Statistical maps depicting brain areas in which the gray matter intensity covaried with four target seeds A. or seed volumes, and B. for separate structural covariance networks C. in all Alzheimer disease patients with the BDNF Met/Met $(n=45)$, Met/Val $(n=86)$ and Val/Val $(n=55)$ genotypes. There was no significant difference in seed volume among the three genotypes $(p>0.05)$. Z-statistic maps $(p<0.05$, corrected with a false discovery rate with extended cluster voxels $>100)$. The images are displayed on a standard brain render. 
(Supplementary Tables 13-15). Of note, in the covariance linking the PCC, frontoinsular and dorsolateral prefrontal seeds, there were no overlapping regions of $\mathrm{Val} / \mathrm{Val}>\mathrm{Val} /$ Met $>$ Met/Met, suggesting a lack of a genetic dosage effect from these three seeds.
Dosage effects $(\mathrm{Val} / \mathrm{Val}>\mathrm{Val} / \mathrm{Met}>\mathrm{Met} / \mathrm{Met})$ of the BDNF val allele via entorhinal seed-based connectivity covariance strength alterations

To investigate whether there was a genetic dosage effect, the volumes of the five peak clusters that were connected with the entorhinal seed were extracted, as they showed significant interactions between $\mathrm{Val} / \mathrm{Val}$ $>$ Met/Met or Val/Met $>$ Met/Met (Figure 3). While the
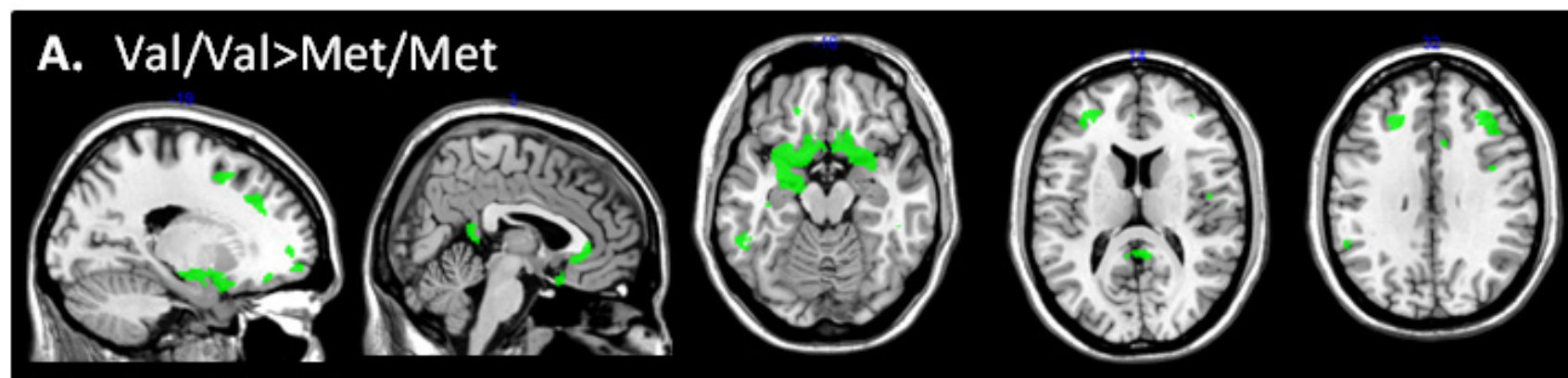

\section{B. Val/Met>Met/Met}
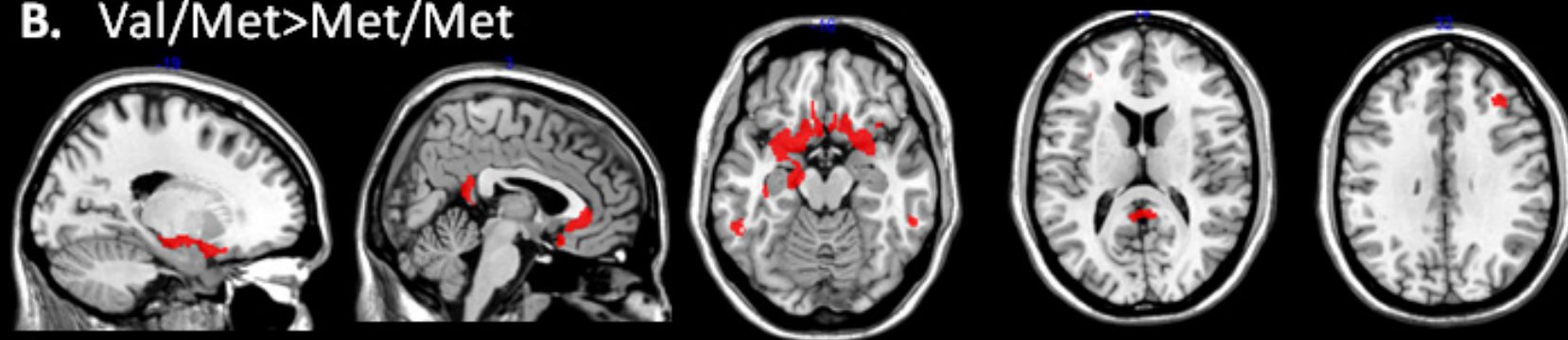

C.
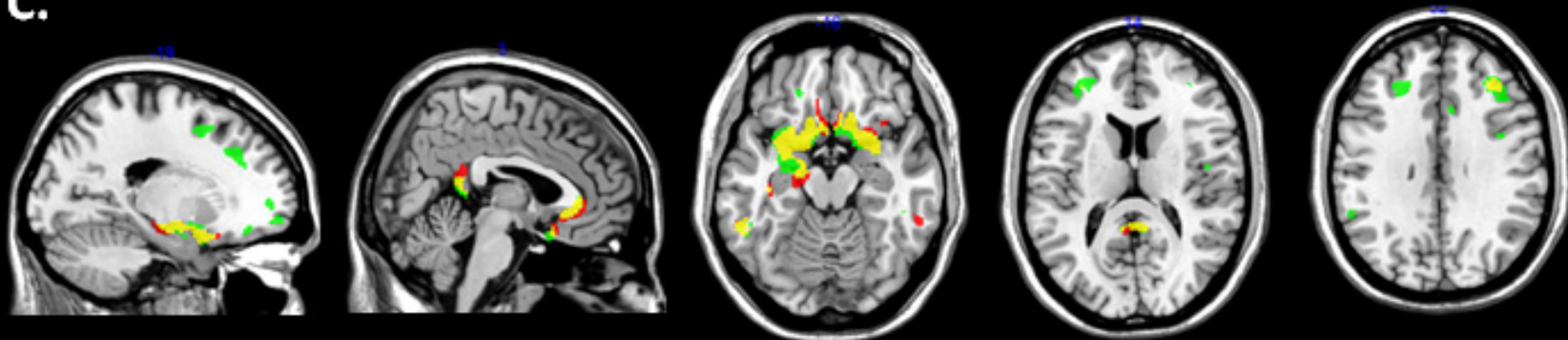

\section{D.}
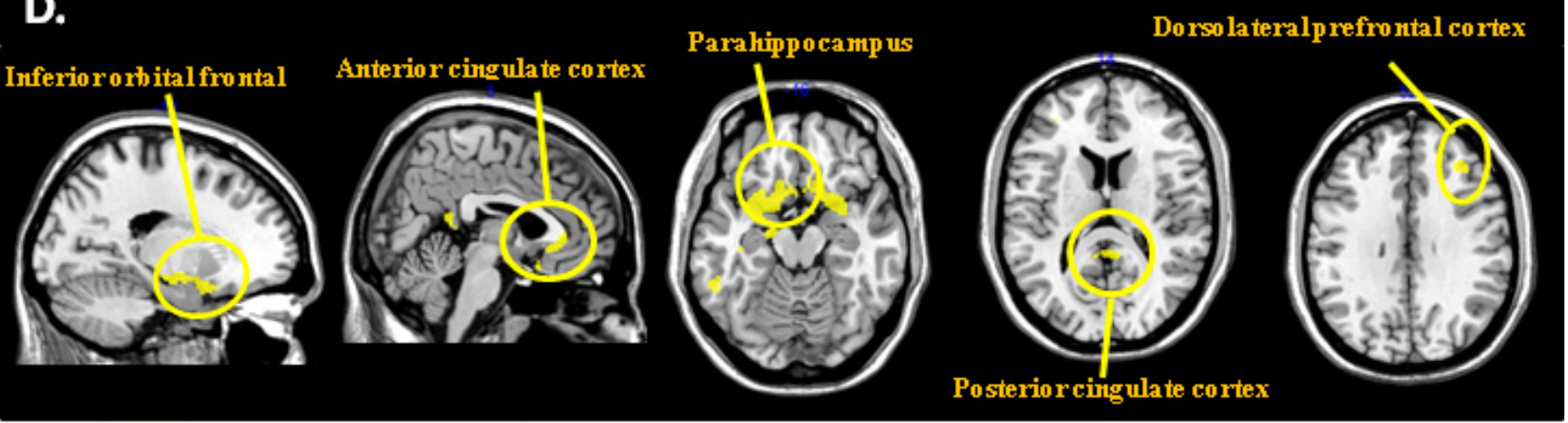

1. Val/Val $>$ Met/Met

2. Val/Met $>$ Met/Met

Overlapping regions of 1 and 2

Figure 2: Peak clusters showing significant interactions of Val/Val $>$ Met/Met (green) or Met/Val $>$ Met/Met (red) from the entorhinal seed. There were five peak clusters showing overlapping of $\mathrm{Val} / \mathrm{Val}>\mathrm{Met} / \mathrm{Val}>\mathrm{Met} / \mathrm{Met}(\mathrm{yellow}) .(\mathrm{x}, \mathrm{y}, \mathrm{z})=$ Montreal Neurological Institute coordinates. 


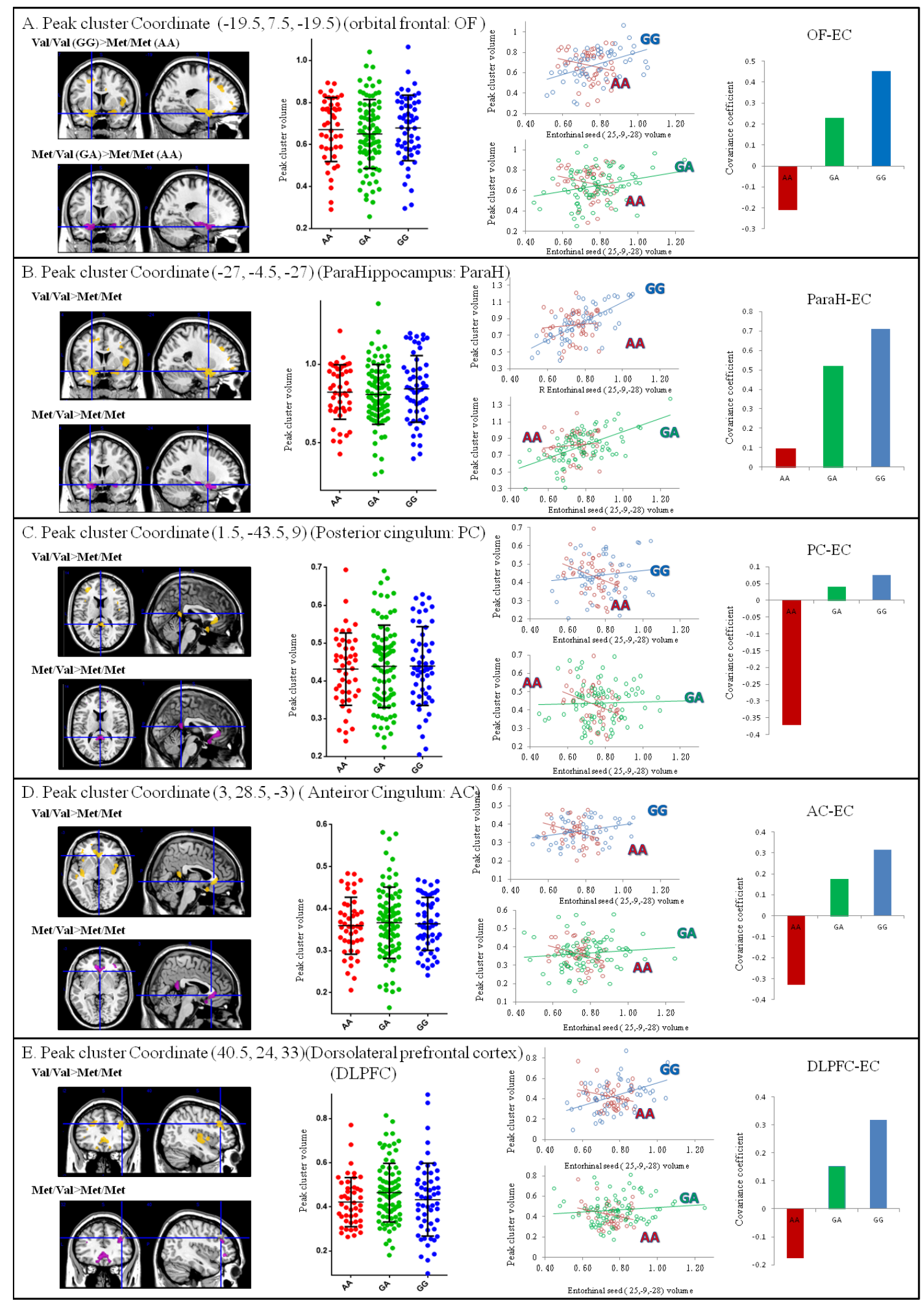

Figure 3: Correlation analysis between entorhinal seed volume and peak cluster volume showing significant interactions of the BDNF genotypes $(\boldsymbol{p}<\mathbf{0 . 0 5})$. The gray matter volumes were extracted from a 4-mm radius sphere in the peak voxel expressing significance. Blue dots and lines represent Val/Val (G homozygotes). Green dots and lines represent Val/Met (GA allele). Red dots and lines represent Met/Met (A homozygotes). No significant changes were found in peak cluster volumes. $(\mathrm{x}, \mathrm{y}, \mathrm{z})=$ Montreal Neurological Institute coordinates. 
entorhinal seed volume (Figure 1B) and seed-connected cluster volume (Figure 3A-3E) were not significantly different among the three genotypes, the genetic dosage effect of the Val allele was via changes in the strength of entorhinal seed-based covariance connectivity (Val/Val $>$ Val/Met > Met/Met) (Figure 3).

\section{Clinical significance of entorhinal seed-related peak clusters showing genotype differences}

The clinical significance of each peak cluster linking to the entorhinal seed showing a genotype effect was evaluated by correlation analysis (Figure 4). Among the five peak cluster volumes and in all three genotypes, only the left orbitofrontal cluster volume (Figure 4A, bold lines) demonstrated significant correlations in predicting MMSE, CASI total scores, CASI orientation and EFT scores.

\section{DISCUSSION}

The results of this study provide data on the network-specific genetic influence of BDNF Val66Met in the early stages of AD. There were three main findings. First, the seed-based SCN pattern validated the hypothesis that the BDNF functional polymorphism targets largescale brain networks rather than selectively in a focal brain region. Second, a genetic dosage effect of the
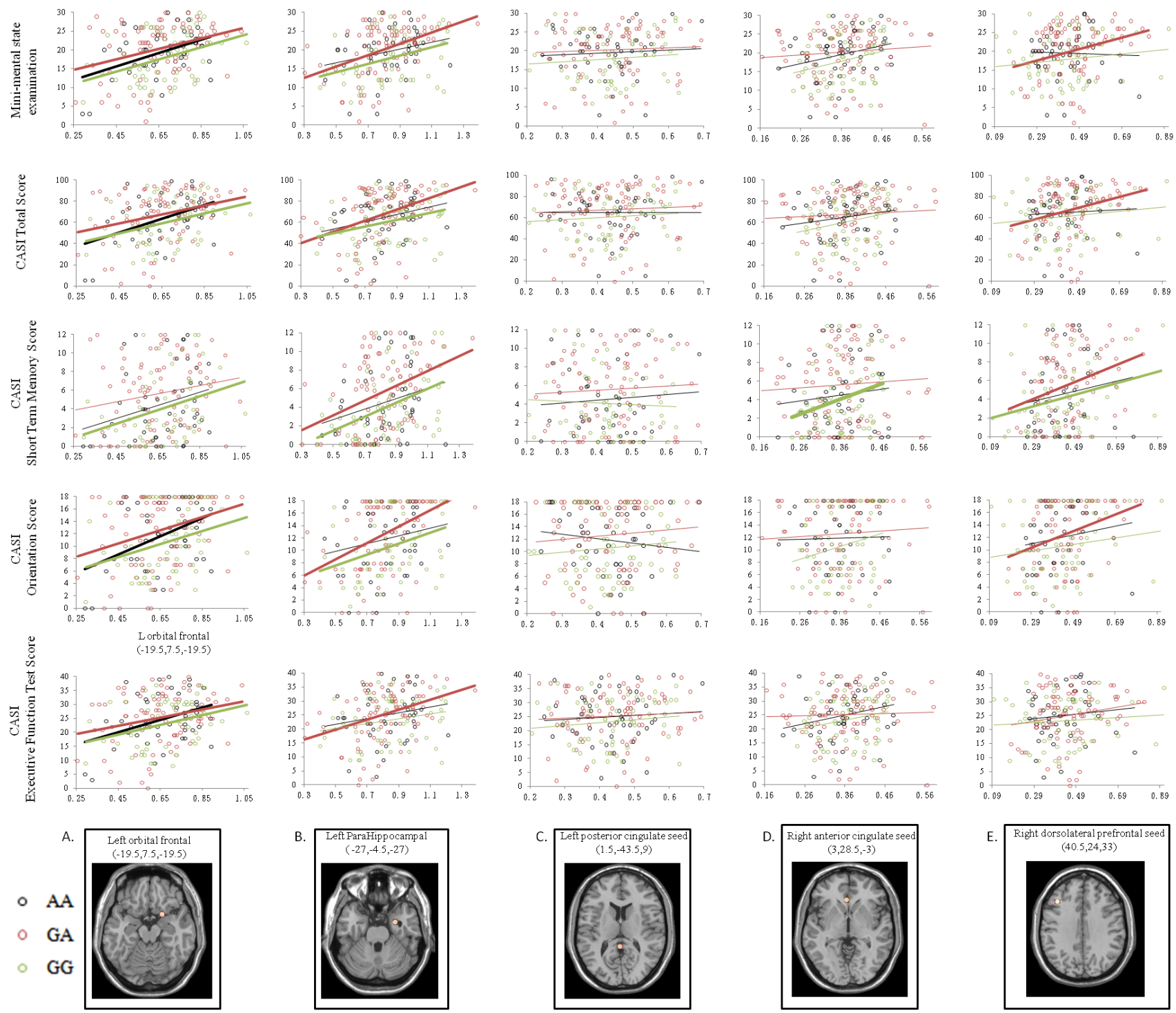

Figure 4: Correlation analysis between cognitive test scores and volume of the peak clusters of the default mode network medial temporal subsystem. Green dots and lines represent Val/Val (G homozygotes). Red dots and lines represent Val/Met (GA allele). Black dots and lines represent Met/Met (A homozygotes). Correlations with statistical significance $(p<0.05)$ in each genotype group are highlighted with thicker lines. $(\mathrm{x}, \mathrm{y}, \mathrm{z})=$ Montreal Neurological Institute coordinates. 
BDNF Val allele was found only in the DMN medial temporal subsystem with cortical hubs consisting of entorhinal, PCC and prefrontal regions. The presence of the genetic dosage effect suggests that the mechanism related to this functional polymorphism may be via modulation of the strength of structural covariance between spatially scattered but functionally coherent regions rather than having a direct impact on the seed or peak cluster volume. Third, while the volumes of the seed and peak clusters of the DMN medial temporal subsystem correlated significantly with cognitive test scores, only the orbitofrontal peak cluster volume predicted cognitive test scores in the three BDNF genotype groups.

\section{Network-specific genetic influence on DMN medial temporal lobe subsystem}

The salient episodic memory impairment in AD has been reported to be strongly associated with hippocampal/ entorhinal volume $[35,36]$, while decreased expressions of BDNF and its receptor, tyrosine receptor kinase B, were also located in the hippocampal and frontal regions [37]. Pathological molecules of the amyloid or tau protein may spread via synaptic connections, and BDNF has been reported to attenuate the neurotoxicity $[5,8]$. The correlation of structural covariance between regions could therefore reveal the genetic effect of $\mathrm{AD}$ at the network level. Taken together with our results, the clinical features, BDNF activity and hippocampal network appear to be highly correlated in the early stages of AD.

While our results suggest that there was no direct effect of BDNF genotype on hippocampal or entorhinal volume, we found that the BDNF genotype may specifically modulate the DMN medial temporal lobe subsystem structural covariance patterns, of which the increased correlations between entorhinal seed and peak clusters demonstrated the genetic dosage effect of the Val allele. While early amyloid burden or GM atrophy has been reported to involve the DMN medial temporal lobe subsystem in the early stage of AD [38], lower BDNF protein levels in the entorhinal cortex seed region have also been reported [39] implying the vulnerability of this region. Therefore, within the entorhinal seed and DMN, BDNF activity can be regarded as an important factor against pathological toxicity.

These alterations can be caused by several factors, and the disease- and genetic-related changes in structural covariance can be difficult to interpret. As the cortical hubs of the DMN are highly functionally anchored, the spatially scattered DMN-related clusters that show structural covariance may validate the notion that BDNF Val66Met polymorphisms only affect activity-dependent pathways [9]. Attenuated correlations between brain regions may suggest disconnectivity related to lower BDNF activity. The explanation of the dosage effect using correlation strength between seed and seed-based connectivity clusters was based on reports that neurons transfected with Met-BDNF show diminished neuronal integrity [9] and less hippocampal dendritic complexity in haploinsufficient BDNF mice [40]. In transgenic mice (BDNF [Met/Met]) [41], normal levels of BDNF have been reported in the brain despite defective secretion from neurons, suggesting the genetic susceptibility of Met homozygotes. As such, the seed region of Met carriers may show less connectivity in mediating the cortical hubs of the DMN network. Alternatively, localized or limited degeneration of a covariance network is also possible in patients with the Met allele [42].

In contrast, stronger correlations modulated by increased BDNF activity may suggest greater regional connectivity and synchronized GM loss in regions targeted by the pathological process. Although the pairwise correlations did not necessarily influence the global organizational properties of structural covariance, as shown by the lack of differences in regional volumes among genotypes, the significant correlations between cognitive outcomes and seed (or peak clusters such as the anterior cingulate, orbitofrontal and dorsolateral prefrontal lobes) volumes within the DMN hubs still address the pathological-genetic alterations of local clustering. The findings of the DMN still reflect segregated and less integrated components in $\mathrm{AD}$ networks that could predict cognitive outcomes.

\section{BDNF genotype polymorphisms target different GM degenerative network patterns}

Among the four seed-based SCNs, the Val (Val/ Val and Val/Met) carriers had more extended voxels of structural covariance in the DMN medial temporal lobe subsystem. In contrast, the Met (Met/Met and Val/ Met) carriers showed stronger structural associations in the DMN midline core system, salience and executive control networks. As BDNF activity was different among the genotypes, the SCN patterns may reflect different strengths of structural covariance between cortical GM and seed region. The SCN patterns may therefore provide evidence that BDNF genotypes target specific large-scale brain networks in patients with $\mathrm{AD}$ that may modulate distinct degenerative patterns. In normal human cortical morphology, Met carriers have been reported to have smaller hippocampal and prefrontal cortical volumes $[12,43]$. However, the genetic effects of Met carriers on smaller entorhinal or prefrontal cortical volumes were not established in this study.

Studies on the genetic risk of developing AD $[10,11]$ or the direct influence of BDNF Val66Met functional polymorphisms on regional volume have reported inconsistent results [12-15, 44]. As significant apolipoprotein $\mathrm{E}$ and BDNF interactions have been 
reported in normal elderly and $\mathrm{AD}$ patients to predict episodic memory performance [45-48], our study design may ignore the epistatic effect of the apolipoprotein $\mathrm{E}$ gene. However, linkage disequilibrium either from other functional polymorphisms in the BDNF gene or from another nearby gene was still possible. Taken together, the strength of connectivity alterations with regards to the interactions of genotypes supports the hypothesis that BDNF functional activity contributes to cognitive outcomes in the early stages of AD, and that this may be mediated by polymorphisms at the Val66Met locus.

Possible explanations why the BDNF genotypes showed inconsistent results on brain structures may be related to epistasis [44], variability in individual hippocampal activity and its neural substrates [49], differences in racial distribution of the Met allele with differences in group strategies for BDNF genotypes [50], and interactions between genotypes and specific intracerebral pathology [51]. In surgically-resected hippocampi from patients with epilepsy, increased levels of BDNF mRNA and protein have been noted, indicating that epileptic activity may up-regulate protein levels via BDNF gene expression $[52,53]$. In patients with chronic epilepsy, however, decreased BDNF secretion has been associated with a decompensated hippocampus [54].As such, secretion of BDNF can be dynamic depending on the integrity of the hippocampus, disease typs and thus the disease stage. We enrolled AD patients with an early stage of disease and the network influence could be different at different stages of disease.

\section{GM alterations reflected the endophenotype of the BDNF genotype}

Despite our observations that BDNF Val66Met polymorphisms may affect structural covariance patterns, there were no significant differences in cognitive measurements in our genotype groups. On the basis of the none-significance in the PCC and dorsolateral prefrontal seed volumes among the three genotype groups, the volumes of both seeds were still significantly correlated with the cognitive scores. The finding supports the hypothesis that brain structure may be considered to be an endophenotype that is more sensitive to a genetic effect than behavioral level. The PCC is an early target of amyloid deposition in both patients with $\mathrm{AD}$ [55] and in cognitively normal subjects with a positive family history of $\mathrm{AD}$ [56]. The dorsolateral prefrontal cortex has been reported to frequently confer executive function, and activation of the prefrontal neural resources have been reported to compensate for the posterior degenerative process [57].

\section{Study limitations}

An important limitation of this study is that we did not include a control group. The effects of BDNF Val66Met genetic variations on regional GM volume and functional state in healthy subjects have been reported $[16,47,50]$. The enrolment of controls may help to understand how the disease interacts with degenerative processes, and whether different genotypes have similar effects on normative structures. Nonetheless, the aim of this study was to determine whether changes in structural correlations between areas of the brain are AD-specific. Our results may provide further evidence reported in healthy elders, that genetic variations of BDNF in AD may mediate SCN patterns and the strength of structural covariance rather than focally. Another potential limitation is that we used seed-based analysis, with an emphasis on the SCNs and reported the genetic dosage effect focusing on the Val allele. The use of independent component analysis [58] or resting state functional MRI data may elucidate whether other networks are involved and also validate the findings of the DMN medial temporal network observed in this study. Finally, as the clinical significance was established in restricted nodes showing peak correlation, whether these nodes were affected by other genetic or biological effects remains an important issue that needs to be tested in further studies. Nonetheless, our genotype groups were carefully matched in major possible confounders, highlighting the unique role of this BDNF functional polymorphism.

\section{CONCLUSIONS}

In summary, our structural covariance analysis supports the role of BDNF functional polymorphisms in modulating the GM degenerative scaffold in the early stages of AD. Our results suggest that the Val66Met functional polymorphism carries different weightings on the DMN, salience and executive control networks. Within the DMN medial temporal lobe subsystem, the genetic dosage effect of the Val allele on entorhinal seedbased SCN was validated by correlation strength gradients between seed and peak clusters, thus supporting the importance of BDNF in AD degenerative network.

\section{MATERIALS AND METHODS}

This study was conducted in accordance with the Declaration of Helsinki and was approved by the Institutional Review Board of Chang Gung Memorial Hospital. The study participants were treated at the Cognition and Aging Center, Department of General Neurology, Kaohsiung Chang Gung Memorial Hospital. A total of 186 subjects (82 males, 104 females) were included after the consensus of a panel composed of 
neurologists, neuropsychologists, neuroradiologists and experts in nuclear medicine [59]. AD was diagnosed according to the International Working Group criteria [60] with a clinical diagnosis of typical AD. All of the patients had a clinical dementia rating scores of 0.5 or 1 , and all of the patients were in a stable condition under treatment with acetylcholine esterase inhibitors from the time of diagnosis. The exclusion criteria were a history of clinical stroke, a modified Hachinski ischemic score $>4$ [61] and depression.

\section{Study working scheme}

The patients were classified into three groups based on the genotype: Met/Met homozygotes $(n=45)$, Met/Val $(n=86)$ and Val/Val homozygotes $(n=55)$. To avoid possible confounding, the three genotype groups were matched for gender, age, educational level, clinical dementia rating [62] and Mini-Mental State Examination (MMSE) scores [63] (Table 1). The working scheme was as follows. First, the SCN was established by seed-based correlation analysis. Seed regions anchoring the DMN (medial temporal subsystem or midline core subsystem), salience and executive control networks were selected to generate SCNs. Differences in each seed regional volume and SCN peak cluster volume were then compared among the three genotype groups. Finally, to evaluate the genetic dosage effects of the Val allele on SCN clusters [9], the SCNs showing significant genotype interactions (i.e. Val/ $\mathrm{Val}>\mathrm{Met} / \mathrm{Met}$ or Met/Val $>$ Met/Met) in seed-peak cluster covariance were modeled. Correlations between peak clusters showing a dosage effect with cognitive test scores were assessed to evaluate the clinical significance.

\section{Clinical and neurobehavioral assessments}

After enrolment, demographic data and a family history of each patient were recorded, and each patient underwent physical and neurological examinations. A trained neuro-psychologist administered the tests. The 30-item MMSE [63] and cognitive ability-screening instrument (CASI) [64] total scores were used as a global assessment of cognitive function. Attention, verbal fluency, abstract thinking, and mental manipulation sub-domain scores of the CASI were used to assess executive function test (EFT) [65], while the non-executive domains included orientation, short- and long-term memory, language ability, and drawing. We used the neuropsychiatric inventory (NPI) to evaluate changes in behavior.

\section{Genotyping}

Genomic DNA was extracted from blood samples using a commercial kit (Qiagen, Gentra Puregene Blood
Kit), followed by genotyping for BDNF Val66Met polymorphisms using the polymerase chain reaction (PCR)-restriction fragment length polymorphism method. Genotyping was conducted with the operator blinded to the clinical data. The apolipoprotein E4 genotype was also determined using a PCR-restriction fragment length polymorphism assay and restriction enzyme HhaI [66]. Apolipoprotein E4 carriers were defined as those with one or two E4 alleles [59].

\section{Cerebrovascular risk confounders}

It has been reported that factors such as oxidative stress, deregulated neuroinflammation and an elevated blood sugar level are related to changes in BDNF expression [67-69]. We included the following cerebrovascular risk confounders: age, homocysteine, total cholesterol, triglycerol, high-density lipoprotein (HDL), low-density lipoprotein (LDL), creatinine, hemoglobin, vitamin B12, folate, and hemoglobin-A1C [36].

\section{Image acquisition}

MR images were acquired using a 3.0T MRI scanner (Excite, GE Medical Systems, Milwaukee, WI, USA). Structural images were acquired for structural covariance analysis using the following protocols: a T1weighted, inversion-recovery-prepared, three-dimensional, gradient-recalled acquisition in a steady-state sequence with a repetition time/echo time/inversion time of 8,600 $\mathrm{ms} / \mathrm{minimal} / 450 \mathrm{~ms}$, a $256 \times 256 \mathrm{~mm}$ field of view, and a 1-mm slice sagittal thickness with a resolution of $0.5 \times$ $0.5 \times 1 \mathrm{~mm}^{3}$.

\section{Data analysis}

Image preprocessing and statistical analysis were performed using SPM8 (SPM8, Wellcome Trust Centre of Cognitive Neurology, University College London, UK, http://www.fil.ion.ucl.ac.uk/spm/). The T1 images were reoriented, realigned, and normalized using the standard Montreal Neurological Institute (MNI) space. The images were then segmented into GM and white matter. Related tissue segments were used to create a custom template using the diffeomorphic anatomical registration using exponentiated lie algebra (DARTEL) approach. The DARTEL approach is one of the highest ranking registration methods in patients with $\mathrm{AD}$ [70]. The modulated and warped images were then smoothed using a Gaussian kernel of $8 \mathrm{~mm}$ full width at half maximum. A direct comparison among the modulated segmented GM volumes of Val/Val homozygotes, Met/Val and Met/ Met homozygotes using voxel-based morphometry [71] showed no significant differences with the threshold set at 
$p<0.05$, corrected for a false discovery rate (FDR) with a cluster size $>100$ voxels.

\section{Statistic analysis}

Clinical and laboratory data were expressed as mean \pm standard deviation. Analysis of variance with Bonferroni correction for multiple comparisons was used to compare levels of cerebrovascular risk biomarkers or continuous variables among the Val/Val homozygotes, and Met/ Val and Met/Met homozygotes. All statistical analyses were conducted using SPSS software (SPSS version 22 for Windows ${ }^{\circledR}$, SPSS Inc., Chicago, IL). Statistical significance was set at $p<0.05$.

To investigate the SCNs, the regional GM volumes of four regions of interest (ROIs) were extracted from the 186 preprocessed images. The seed ROI included the right entorhinal cortex (coordinates: 25,-9,-28), left posterior cingulate cortex (PCC; coordinates: -2,-36, 35), right frontoinsular cortex (coordinates: $38,26,-10$ ), and right dorsolateral prefrontal cortex (coordinates: 44, 36, 20) (Figure 1A). According to the literature, these regions anchor the DMN medial temporal subsystem (right entorhinal cortex) [72], DMN midline core subsystem (left PCC) [73, 74], salience network (right frontoinsular cortex), and executive network (right dorsolateral prefrontal cortex) [23]. As the pathology or functional connectivity in typical patients with $\mathrm{AD}$ is distributed symmetrically, we did not perform a contralateral seed analysis in this study.

From the modified GM images, the GM volumes of a 4-mm radius sphere around the seed ROI coordinates were calculated, followed by four separate correlation analyses using the extracted GM volumes as the covariates of interest. The three BDNF genotype groups were modeled separately. For each BDNF genotype group, specific contrasts were set to identify voxels that showed positive correlations for each seed ROI. The results reflected the SCNs of each ROI and the threshold was set at $p<0.01$, corrected for FDR with a cluster size $>100$ voxels.

In addition, to investigate how genetic variance may interfere with structural covariance patterns, voxels showing significant differences in the regression slopes in each seed-peak cluster correlations were compared, pointing to possible interactions between $\mathrm{Val} / \mathrm{Val}>\mathrm{Met} /$ Met or Val/Met $>$ Met/Met. The genetic dosage model was based on an in vivo study in which the expression of BDNF was found to be highest in Val/Val, followed by Val/Met and Met/Met [75]. Specific t contrasts were established to map the voxels that expressed significant between-group associations. The threshold for the resulting statistical parametric maps was set at $p<0.001$ (uncorrected) with a cluster size $>100$ voxels. In addition, for the peak clusters showing significant between-group differences, a 4-mm radius sphere was placed on the peak voxel, and the GM volumes were then calculated for regression analysis. The seed ROI was considered to be the predictive variable for the extracted SCN peak voxel, and the threshold was set at $p<0.05$ with multiple corrections. To evaluate the clinical significance of the seed or identified peak voxel, we used a linear regression model with the cognitive test scores serving as the dependent variable. The threshold was set at $p<0.05$ with multiple corrections.

\section{ACKNOWLEDGMENTS}

The authors wish to thank the patients and their caregivers for their time and commitment to this research.

\section{CONFLICTS OF INTEREST}

The authors have no conflicts of interest.

\section{GRANT SUPPORT}

This work was supported by grants CMRPG8C0571 and CMRPG8D0771 from Chang Gung Memorial Hospital, and 104-2314-B-182A-026-MY2 from the National Science Council to CCC.

\section{REFERENCES}

1. Schinder AF and Poo M. The neurotrophin hypothesis for synaptic plasticity. Trends Neurosci. 2000; 23:639-645.

2. Huang EJ and Reichardt LF. Neurotrophins: roles in neuronal development and function. Annu Rev Neurosci. 2001; 24:677-736.

3. Conner JM, Lauterborn JC, Yan Q, Gall CM and Varon S. Distribution of brain-derived neurotrophic factor (BDNF) protein and mRNA in the normal adult rat CNS: evidence for anterograde axonal transport. J Neurosci. 1997; 17:2295-2313.

4. Yan Q, Rosenfeld RD, Matheson CR, Hawkins N, Lopez OT, Bennett L and Welcher AA. Expression of brainderived neurotrophic factor protein in the adult rat central nervous system. Neuroscience. 1997; 78:431-448.

5. Aicardi G, Argilli E, Cappello S, Santi S, Riccio M, Thoenen $\mathrm{H}$ and Canossa $\mathrm{M}$. Induction of long-term potentiation and depression is reflected by corresponding changes in secretion of endogenous brain-derived neurotrophic factor. Proc Natl Acad Sci U S A. 2004; 101:15788-15792.

6. Korte M, Griesbeck O, Gravel C, Carroll P, Staiger V, Thoenen $\mathrm{H}$ and Bonhoeffer $\mathrm{T}$. Virus-mediated gene transfer into hippocampal CA1 region restores long-term potentiation in brain-derived neurotrophic factor mutant mice. Proc Natl Acad Sci U S A. 1996; 93:12547-12552.

7. Gorski JA, Balogh SA, Wehner JM and Jones KR. Learning deficits in forebrain-restricted brain-derived neurotrophic 
factor mutant mice. Neuroscience. 2003; 121:341-354.

8. Poo MM. Neurotrophins as synaptic modulators. Nat Rev Neurosci. 2001; 2:24-32.

9. Egan MF, Kojima M, Callicott JH, Goldberg TE, Kolachana BS, Bertolino A, Zaitsev E, Gold B, Goldman D, Dean $\mathrm{M}, \mathrm{Lu} \mathrm{B}$ and Weinberger DR. The BDNF val66met polymorphism affects activity-dependent secretion of BDNF and human memory and hippocampal function. Cell. 2003; 112:257-269.

10. Ji H, Dai D, Wang Y, Jiang D, Zhou X, Lin P, Ji X, Li J, Zhang Y, Yin H, Chen R, Zhang L, Xu M, Duan S and Wang Q. Association of and with Alzheimer's disease: Meta-analysis based on 56 genetic case-control studies of 12,563 cases and 12,622 controls. Exp Ther Med. 2015; 9:1831-1840.

11. Fukumoto N, Fujii T, Combarros O, Kamboh MI, Tsai SJ, Matsushita S, Nacmias B, Comings DE, Arboleda H, Ingelsson M, Hyman BT, Akatsu H, Grupe A, Nishimura AL, Zatz M, Mattila KM, et al. Sexually dimorphic effect of the Val66Met polymorphism of BDNF on susceptibility to Alzheimer's disease: New data and meta-analysis. Am J Med Genet B Neuropsychiatr Genet. 2010; 153B:235-242.

12. Pezawas L, Verchinski BA, Mattay VS, Callicott JH, Kolachana BS, Straub RE, Egan MF, Meyer-Lindenberg A and Weinberger DR. The brain-derived neurotrophic factor val66met polymorphism and variation in human cortical morphology. J Neurosci. 2004; 24:10099-10102.

13. Bueller JA, Aftab M, Sen S, Gomez-Hassan D, Burmeister $\mathrm{M}$ and Zubieta JK. BDNF Val66Met allele is associated with reduced hippocampal volume in healthy subjects. Biol Psychiatry. 2006; 59:812-815.

14. Montag C, Weber B, Fliessbach K, Elger C and Reuter M. The BDNF Val66Met polymorphism impacts parahippocampal and amygdala volume in healthy humans: incremental support for a genetic risk factor for depression. Psychol Med. 2009; 39:1831-1839.

15. Karnik MS, Wang L, Barch DM, Morris JC and Csernansky JG. BDNF polymorphism rs6265 and hippocampal structure and memory performance in healthy control subjects. Psychiatry Res. 2010; 178:425-429.

16. Tsai SJ, Gau YT, Liu ME, Hsieh CH, Liou YJ and Hong CJ. Association study of brain-derived neurotrophic factor and apolipoprotein E polymorphisms and cognitive function in aged males without dementia. Neurosci Lett. 2008; 433:158-162.

17. Gonul AS, Kitis O, Eker MC, Eker OD, Ozan E and Coburn K. Association of the brain-derived neurotrophic factor Val66Met polymorphism with hippocampus volumes in drug-free depressed patients. World J Biol Psychiatry. 2011; 12:110-118.

18. Oroszi G, Lapteva L, Davis E, Yarboro CH, Weickert T, Roebuck-Spencer T, Bleiberg J, Rosenstein D, Pao M, Lipsky PE, Goldman D, Lipsky RH and Illei GG. The Met66 allele of the functional Val66Met polymorphism in the brain-derived neurotrophic factor gene confers protection against neurocognitive dysfunction in systemic lupus erythematosus. Ann Rheum Dis. 2006; 65:1330-1335.

19. Ramasamy DP, Ramanathan M, Cox JL, Antulov R, Weinstock-Guttman B, Bergsland N, Benedict RH, Dwyer MG, Minagar A and Zivadinov R. Effect of Met66 allele of the BDNF rs6265 SNP on regional gray matter volumes in patients with multiple sclerosis: A voxel-based morphometry study. Pathophysiology. 2011; 18:53-60.

20. Greicius MD, Srivastava G, Reiss AL and Menon V. Default-mode network activity distinguishes Alzheimer's disease from healthy aging: evidence from functional MRI. Proc Natl Acad Sci U S A. 2004; 101:4637-4642.

21. Greicius MD, Supekar K, Menon V and Dougherty RF. Resting-state functional connectivity reflects structural connectivity in the default mode network. Cereb Cortex. 2009; 19:72-78.

22. Seeley WW, Allman JM, Carlin DA, Crawford RK, Macedo MN, Greicius MD, Dearmond SJ and Miller BL. Divergent social functioning in behavioral variant frontotemporal dementia and Alzheimer disease: reciprocal networks and neuronal evolution. Alzheimer Dis Assoc Disord. 2007; 21:S50-57.

23. Seeley WW, Menon V, Schatzberg AF, Keller J, Glover GH, Kenna H, Reiss AL and Greicius MD. Dissociable intrinsic connectivity networks for salience processing and executive control. J Neurosci. 2007; 27:2349-2356.

24. Agosta F, Pievani M, Geroldi C, Copetti M, Frisoni GB and Filippi M. Resting state fMRI in Alzheimer's disease: beyond the default mode network. Neurobiol Aging. 2012; 33:1564-1578.

25. Filippi M, Agosta F, Scola E, Canu E, Magnani G, Marcone A, Valsasina P, Caso F, Copetti M, Comi G, Cappa SF and Falini A. Functional network connectivity in the behavioral variant of frontotemporal dementia. Cortex. 2013; 49:23892401.

26. Andrews-Hanna JR, Reidler JS, Sepulcre J, Poulin R and Buckner RL. Functional-anatomic fractionation of the brain's default network. Neuron. 2010; 65:550-562.

27. Chhatwal JP, Schultz AP, Johnson K, Benzinger TL, Jack C, Jr., Ances BM, Sullivan CA, Salloway SP, Ringman JM, Koeppe RA, Marcus DS, Thompson P, Saykin AJ, Correia S, Schofield PR, Rowe CC, et al. Impaired default network functional connectivity in autosomal dominant Alzheimer disease. Neurology. 2013; 81:736-744.

28. Hong SB, Zalesky A, Park S, Yang YH, Park MH, Kim B, Song IC, Sohn CH, Shin MS, Kim BN, Cho SC and Kim JW. COMT genotype affects brain white matter pathways in attention-deficit/hyperactivity disorder. Hum Brain Mapp. 2015; 36:367-377.

29. Thompson PM, Ge T, Glahn DC, Jahanshad N and Nichols TE. Genetics of the connectome. Neuroimage. 2013; 80:475-488.

30. Zeidan-Chulia F, de Oliveira BH, Salmina AB, Casanova 
MF, Gelain DP, Noda M, Verkhratsky A and Moreira JC. Altered expression of Alzheimer's disease-related genes in the cerebellum of autistic patients: a model for disrupted brain connectome and therapy. Cell Death Dis. 2014; 5:e1250.

31. Levine ME, Lu AT, Bennett DA and Horvath S. Epigenetic age of the pre-frontal cortex is associated with neuritic plaques, amyloid load, and Alzheimer's disease related cognitive functioning. Aging (Albany NY). 2015; 7:11981211. doi: 10.18632/aging.100864.

32. Currais A, Goldberg J, Farrokhi C, Chang M, Prior M, Dargusch R, Daugherty D, Armando A, Quehenberger O, Maher $\mathrm{P}$ and Schubert D. A comprehensive multiomics approach toward understanding the relationship between aging and dementia. Aging (Albany NY). 2015; 7:937-955. doi: 10.18632/aging.100838.

33. Bredesen DE. Metabolic profiling distinguishes three subtypes of Alzheimer's disease. Aging (Albany NY). 2015; 7:595-600. doi: 10.18632/aging.100801.

34. Bredesen DE. Reversal of cognitive decline: a novel therapeutic program. Aging (Albany NY). 2014; 6:707-717. doi: 10.18632/aging.100690.

35. Tsai RM, Leong JK, Dutt S, Chang CC, Lee AK, Chao SZ, Yokoyama JS, Tse M, Kramer JH, Miller BL and Rosen HJ. The Chinese Verbal Learning Test specifically assesses hippocampal state. Am J Alzheimers Dis Other Demen. 2015; 30:412-416.

36. Wu MK, Lu YT, Huang CW, Lin PH, Chen NC, Lui CC, Chang WN, Lee CC, Chang YT, Chen SF and Chang CC. Clinical Significance of Cerebrovascular Biomarkers and White Matter Tract Integrity in Alzheimer Disease: Clinical correlations With Neurobehavioral Data in Cross-Sectional and After 18 Months Follow-ups. Medicine (Baltimore). 2015; 94:e1192.

37. Ferrer I, Marin C, Rey MJ, Ribalta T, Goutan E, Blanco R, Tolosa E and Marti E. BDNF and full-length and truncated TrkB expression in Alzheimer disease. Implications in therapeutic strategies. J Neuropathol Exp Neurol. 1999; 58:729-739.

38. Chang YT, Huang CW, Chang YH, Chen NC, Lin KJ, Yan TC, Chang WN, Chen SF, Lui CC, Lin PH and Chang CC. Amyloid burden in the hippocampus and default mode network: relationships with gray matter volume and cognitive performance in mild stage Alzheimer disease. Medicine (Baltimore). 2015; 94:e763.

39. Hock C, Heese K, Hulette C, Rosenberg C and Otten U. Region-specific neurotrophin imbalances in Alzheimer disease: decreased levels of brain-derived neurotrophic factor and increased levels of nerve growth factor in hippocampus and cortical areas. Arch Neurol. 2000; 57:846-851.

40. Magarinos AM, Li CJ, Gal Toth J, Bath KG, Jing D, Lee FS and McEwen BS. Effect of brain-derived neurotrophic factor haploinsufficiency on stress-induced remodeling of hippocampal neurons. Hippocampus. 2011; 21:253-264.
41. Chen ZY, Jing D, Bath KG, Ieraci A, Khan T, Siao CJ, Herrera DG, Toth M, Yang C, McEwen BS, Hempstead BL and Lee FS. Genetic variant BDNF (Val66Met) polymorphism alters anxiety-related behavior. Science. 2006; 314:140-143.

42. Alexander-Bloch A, Giedd JN and Bullmore E. Imaging structural co-variance between human brain regions. Nat Rev Neurosci. 2013; 14:322-336.

43. Molendijk ML, Bus BA, Spinhoven P, Kaimatzoglou A, Oude Voshaar RC, Penninx BW, van IMH and Elzinga BM. A systematic review and meta-analysis on the association between BDNF val(66)met and hippocampal volume-a genuine effect or a winners curse? Am J Med Genet B Neuropsychiatr Genet. 2012; 159B:731-740.

44. Pezawas L, Meyer-Lindenberg A, Goldman AL, Verchinski BA, Chen G, Kolachana BS, Egan MF, Mattay VS, Hariri $\mathrm{AR}$ and Weinberger DR. Evidence of biologic epistasis between BDNF and SLC6A4 and implications for depression. Mol Psychiatry. 2008; 13:709-716.

45. Ward DD, Summers MJ, Saunders NL, Janssen P, Stuart KE and Vickers JC. APOE and BDNF Val66Met polymorphisms combine to influence episodic memory function in older adults. Behav Brain Res. 2014; 271:309315 .

46. Alvarez A, Aleixandre M, Linares C, Masliah E and Moessler H. Apathy and APOE4 are associated with reduced BDNF levels in Alzheimer's disease. J Alzheimers Dis. 2014; 42:1347-1355.

47. Liu YH, Jiao SS, Wang YR, Bu XL, Yao XQ, Xiang Y, Wang QH, Wang L, Deng J, Li J, Zhou XF, Zhou HD and Wang YJ. Associations Between ApoEepsilon4 Carrier Status and Serum BDNF Levels-New Insights into the Molecular Mechanism of ApoEepsilon4 Actions in Alzheimer's Disease. Mol Neurobiol. 2015; 51:1271-1277.

48. Richter-Schmidinger T, Alexopoulos P, Horn M, Maus S, Reichel M, Rhein C, Lewczuk P, Sidiropoulos C, Kneib T, Perneczky R, Doerfler A and Kornhuber J. Influence of brain-derived neurotrophic-factor and apolipoprotein E genetic variants on hippocampal volume and memory performance in healthy young adults. J Neural Transm (Vienna). 2011; 118:249-257.

49. Kambeitz JP, Bhattacharyya S, Kambeitz-Ilankovic LM, Valli I, Collier DA and McGuire P. Effect of BDNF val(66) met polymorphism on declarative memory and its neural substrate: a meta-analysis. Neurosci Biobehav Rev. 2012; 36:2165-2177.

50. Liu ME, Huang CC, Chen MH, Yang AC, Tu PC, Yeh HL, Hong CJ, Chen JF, Hwang JP, Lin CP and Tsai SJ. Effect of the BDNF Val66Met polymorphism on regional gray matter volumes and cognitive function in the Chinese population. Neuromolecular Med. 2014; 16:127-136.

51. Huang CC, Liu ME, Chou KH, Yang AC, Hung CC, Hong CJ, Tsai SJ and Lin CP. Effect of BDNF Val66Met polymorphism on regional white matter hyperintensities and cognitive function in elderly males without dementia. 
Psychoneuroendocrinology. 2014; 39:94-103.

52. Wang FJ, Li CM, Hou XH, Wang XR and Zhang LM. Selective upregulation of brain-derived neurotrophic factor (BDNF) transcripts and BDNF direct induction of activity independent N-methyl-D-aspartate currents in temporal lobe epilepsy patients with hippocampal sclerosis. J Int Med Res. 2011; 39:1358-1368.

53. Murray KD, Isackson PJ, Eskin TA, King MA, Montesinos SP, Abraham LA and Roper SN. Altered mRNA expression for brain-derived neurotrophic factor and type II calcium/ calmodulin-dependent protein kinase in the hippocampus of patients with intractable temporal lobe epilepsy. J Comp Neurol. 2000; 418:411-422.

54. LaFrance WC, Jr., Leaver K, Stopa EG, Papandonatos GD and Blum AS. Decreased serum BDNF levels in patients with epileptic and psychogenic nonepileptic seizures. Neurology. 2010; 75:1285-1291.

55. Li Y, Rinne JO, Mosconi L, Pirraglia E, Rusinek H, DeSanti S, Kemppainen N, Nagren K, Kim BC, Tsui W and de Leon MJ. Regional analysis of FDG and PIB-PET images in normal aging, mild cognitive impairment, and Alzheimer's disease. Eur J Nucl Med Mol Imaging. 2008; 35:2169-2181.

56. Mosconi L, Rinne JO, Tsui WH, Berti V, Li Y, Wang H, Murray J, Scheinin N, Nagren K, Williams S, Glodzik L, De Santi S, Vallabhajosula S and de Leon MJ. Increased fibrillar amyloid-\{beta\} burden in normal individuals with a family history of late-onset Alzheimer's. Proc Natl Acad Sci U S A. 2010; 107:5949-5954.

57. Grady CL, McIntosh AR, Beig S, Keightley ML, Burian H and Black SE. Evidence from functional neuroimaging of a compensatory prefrontal network in Alzheimer's disease. J Neurosci. 2003; 23:986-993.

58. Beckmann CF, DeLuca M, Devlin JT and Smith SM. Investigations into resting-state connectivity using independent component analysis. Philos Trans R Soc Lond B Biol Sci. 2005; 360:1001-1013.

59. Huang CW, Tsai MH, Chen NC, Chen WH, Lu YT, Lui CC, Chang YT, Chang WN, Chang AY and Chang CC. Clinical significance of circulating vascular cell adhesion molecule-1 to white matter disintegrity in Alzheimer's dementia. Thromb Haemost. 2015; 114:1230-1240.

60. Dubois B, Feldman HH, Jacova C, Cummings JL, Dekosky ST, Barberger-Gateau P, Delacourte A, Frisoni G, Fox NC, Galasko D, Gauthier S, Hampel H, Jicha GA, Meguro K, O'Brien J, Pasquier F, et al. Revising the definition of Alzheimer's disease: a new lexicon. Lancet Neurol. 2010; 9:1118-1127.

61. Rosen WG, Terry RD, Fuld PA, Katzman R and Peck A. Pathological verification of ischemic score in differentiation of dementias. Ann Neurol. 1980; 7:486-488.

62. Morris JC. The Clinical Dementia Rating (CDR): current version and scoring rules. Neurology. 1993; 43:2412-2414.

63. Folstein MF, Folstein SE and McHugh PR. "Mini-mental state". A practical method for grading the cognitive state of patients for the clinician. J Psychiatr Res. 1975; 12:189-198.

64. Teng EL, Hasegawa K, Homma A, Imai Y, Larson E, Graves A, Sugimoto K, Yamaguchi T, Sasaki H, Chiu D and et al. The Cognitive Abilities Screening Instrument (CASI): a practical test for cross-cultural epidemiological studies of dementia. Int Psychogeriatr. 1994; 6:45-58; discussion 62.

65. Huang CW, Chang WN, Huang SH, Lui CC, Chen NC, Chang YT, Lee CC, Chang CC and Chang AY. Impact of homocysteine on cortical perfusion and cognitive decline in mild Alzheimer's dementia. Eur J Neurol. 2013; 20:11911197.

66. Del Bo R, Comi GP, Bresolin N, Castelli E, Conti E, Degiuli A, Ausenda CD and Scarlato G. The apolipoprotein E epsilon4 allele causes a faster decline of cognitive performances in Down's syndrome subjects. J Neurol Sci. 1997; 145:87-91.

67. Yang T, Zhou D and Stefan H. Why mesial temporal lobe epilepsy with hippocampal sclerosis is progressive: uncontrolled inflammation drives disease progression? J Neurol Sci. 2010; 296:1-6.

68. Zhao HF, Li Q and Li Y. Long-term ginsenoside administration prevents memory loss in aged female C57BL/6J mice by modulating the redox status and upregulating the plasticity-related proteins in hippocampus. Neuroscience. 2011; 183:189-202.

69. Bus BA, Molendijk ML, Penninx BJ, Buitelaar JK, Kenis G, Prickaerts J, Elzinga BM and Voshaar RC. Determinants of serum brain-derived neurotrophic factor. Psychoneuroendocrinology. 2011; 36:228-239.

70. Cuingnet R, Gerardin E, Tessieras J, Auzias G, Lehericy S, Habert MO, Chupin M, Benali H and Colliot O. Automatic classification of patients with Alzheimer's disease from structural MRI: a comparison of ten methods using the ADNI database. Neuroimage. 2011; 56:766-781.

71. Ashburner J and Friston KJ. Voxel-based morphometrythe methods. Neuroimage. 2000; 11:805-821.

72. Bernhardt BC, Worsley KJ, Besson P, Concha L, Lerch JP, Evans AC and Bernasconi N. Mapping limbic network organization in temporal lobe epilepsy using morphometric correlations: insights on the relation between mesiotemporal connectivity and cortical atrophy. Neuroimage. 2008; 42:515-524.

73. Spreng $\mathrm{RN}$ and Turner GR. Structural covariance of the default network in healthy and pathological aging. $\mathrm{J}$ Neurosci. 2013; 33:15226-15234.

74. Zielinski BA, Anderson JS, Froehlich AL, Prigge MB, Nielsen JA, Cooperrider JR, Cariello AN, Fletcher PT, Alexander AL, Lange N, Bigler ED and Lainhart JE. scMRI reveals large-scale brain network abnormalities in autism. PLoS One. 2012; 7:e49172.

75. Hsu PK, Xu B, Mukai J, Karayiorgou M and Gogos JA. The BDNF Val66Met variant affects gene expression through miR-146b. Neurobiol Dis. 2015; 77:228-237. 